\title{
A computational fluid dynamics (CFD) analysis of fluid excitations on the spindle in a high-pressure valve
}

DOI:

10.1016/j.ijpvp.2019.103922

\section{Document Version}

Accepted author manuscript

Link to publication record in Manchester Research Explorer

\section{Citation for published version (APA):}

Duan, Y., Revell, A., Sinha, J., \& Hahn, W. (2019). A computational fluid dynamics (CFD) analysis of fluid excitations on the spindle in a high-pressure valve. International Journal of Pressure Vessels and Piping, 175, 103922. https://doi.org/10.1016/j.ijpvp.2019.103922

\section{Published in:}

International Journal of Pressure Vessels and Piping

\section{Citing this paper}

Please note that where the full-text provided on Manchester Research Explorer is the Author Accepted Manuscript or Proof version this may differ from the final Published version. If citing, it is advised that you check and use the publisher's definitive version.

\section{General rights}

Copyright and moral rights for the publications made accessible in the Research Explorer are retained by the authors and/or other copyright owners and it is a condition of accessing publications that users recognise and abide by the legal requirements associated with these rights.

\section{Takedown policy}

If you believe that this document breaches copyright please refer to the University of Manchester's Takedown Procedures [http://man.ac.uk/04Y6Bo] or contact uml.scholarlycommunications@manchester.ac.uk providing relevant details, so we can investigate your claim.

\section{OPEN ACCESS}




\title{
A computational fluid dynamics (CFD) analysis of fluid excitations on the spindle in a high-pressure valve
}

\author{
Yu Duan ${ }^{1,2 *}$; Alistair Revell ${ }^{1 *}$; Jyoti Sinha ${ }^{1}$; Wolfgang Hahn ${ }^{1,3}$ \\ 1. School of Mechanical, Aerospace and Civil Engineering, University of Manchester, \\ Manchester, M13 9PL, UK. \\ 2. Department of Mechanical Engineering, Imperial College London, London, SW7 2AZ \\ 3. EDF Energy, Barnwood, Gloucester GL4 3RS, UK
}

\begin{abstract}
There have been a number of significant power outages caused by unexpected levels of flowinduced vibration of valves in partially-open operating conditions and as such the understanding of this phenomena is critically important. On-site testing is normally expensive and inherently difficult given typical flow rates but while computational fluid dynamics (CFD) offers a feasible alternative, it demands careful use and analysis to capture the highly coupled physical phenomena present. This paper reports on the fluid flow around a spindle in a highpressure valve and related flow by means of 2D unsteady Reynolds-Averaged Navier-Stokes (URANS) equations and the $k-\omega-S S T$ turbulence model. Following a mesh sensitivity study, the measured force frequencies and shockwave patterns predicted around the valve head indicate a high level of agreement with experimental reference data. The unsteady flow is then assessed at various stages of valve-opening; conditions which are increasingly common in the context of power throttling to balance supply from more variable renewable energy sources. Although, the averaged force on the valve head reduces linearly with the lift of stem, the fluctuating component of the force rises by almost $50 \%$ when the valve opening changes from $25 \%$ to $50 \%$. This quantity, significant in the identification of violent high-frequency vibration, is then observed to reduce steadily upon further opening. Spectral analysis and flow field data provide the basis for further insight with respect to the formation and evolution of a series of shock-wave/boundary-layer interactions along the valve head.
\end{abstract}

Keywords: CFD analysis; Fluid excitation; Unstable valve flow; Shock-wave/boundary-layer interactions.

\footnotetext{
* Corresponding author: y.duan@imperial.ac.uk; alistair.revell@manchester.ac.uk
} 


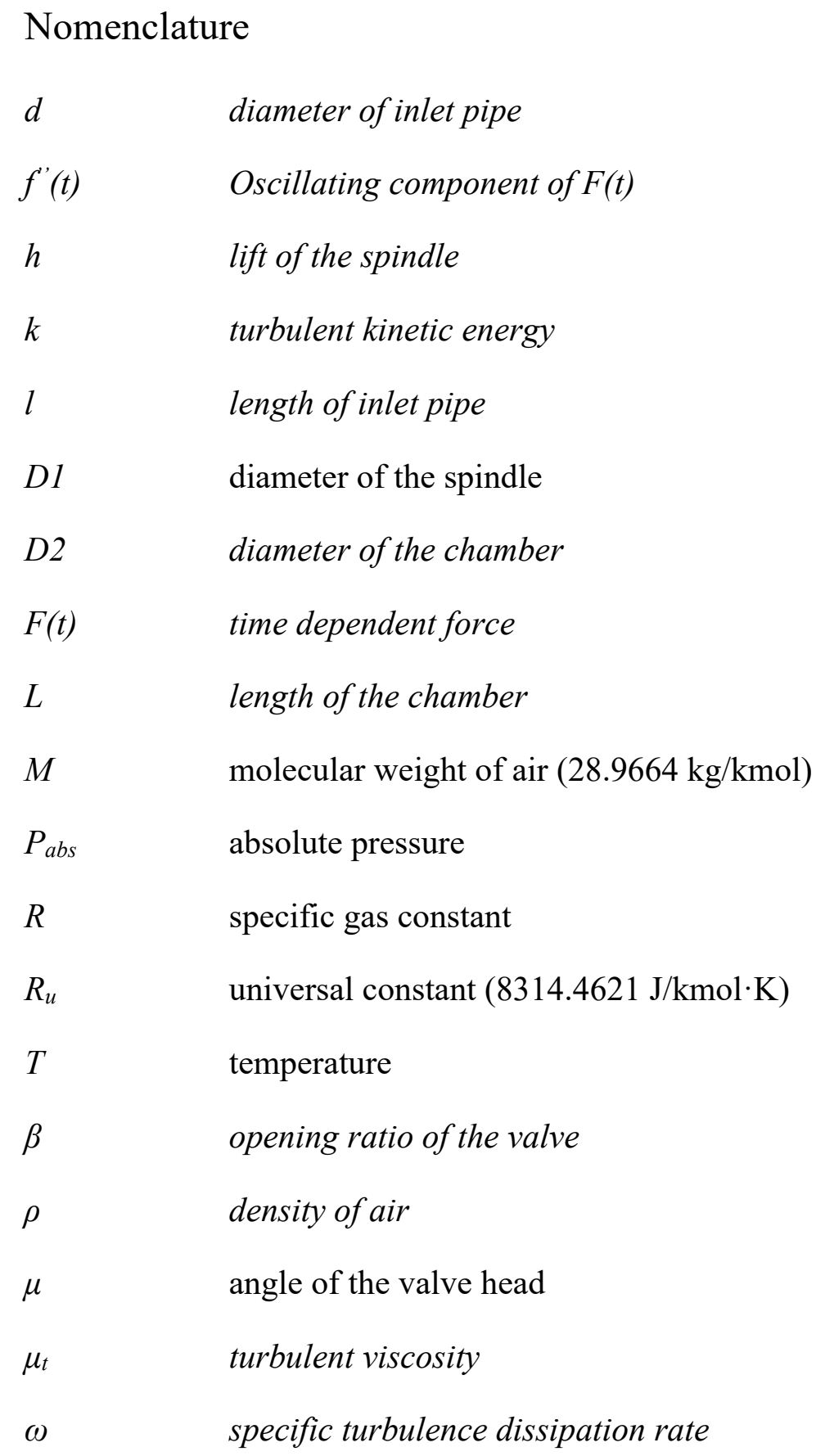




\section{Introduction}

The high-pressure throttle valve is used to control the output of the steam turbine via controlling the mass-flow rate. A large amount of the flow energy is dissipated and converted to vibrations and noise in the vicinity of the valve. The ability to predict how flow rate and valve opening condition may give rise to high frequency flow-induced vibration is of critical importance to the power industry; in order to be able to reduce or entirely eliminate instances of dynamic events which can lead to structural damage and failure in very short time frames [1]. Many such events have been reported to occur when the valves were partially open, resulting in violent vibrations of valve components such as stem, suspension elements, and valve seat. Regardless of the operational mode and design, the excitation frequencies, expected to cause high vibration, are likely to be in the range of $100 \mathrm{~Hz}$ to a few $\mathrm{kHz}$. The vibration in the throttle valve may also extend to other steam turbine components, resulting in damage and reduced lifespan of the rotor and turbine blades [2,3]. Due to the recent rapid development of the renewable energy sector, the capacity for wind and solar power generation deployed on a responsive basis (according to favourable conditions) is increased. As such, the output from thermal power stations, including nuclear power, is required to change more often than before. While power plants are throttled to a lower level for short intervals, long term operation with partially-opened valve becomes more common. To ensure reliable operation under the offdesign condition, the dynamic forces on the valve head induced by unsteady flow must be better understood for a much broader range of operating conditions than before.

The flow instability in the turbine control valves can be due to many reasons, such as the Coanda effect, supersonic flow, flow separation, shear layer, steam expansion, and bubble separation [4]. Araki et al. [5] reviewed the studies, done in the former USSR, on the forced vibration of the mushroom-like valve plug in the axial and lateral direction. The stability of the pressure field around the valve head was identified to be dependent on the flow pattern downstream the valve head. Different flow patterns were caused by the various operational modes, namely, the pressure ratio and the valve openings. This theory was adopted in [6] and [7] to explain damages of the steam turbine throttle valve, which is reported in [8]. It was demonstrated in these studies that the asymmetric flow separation around the partially-opened valve head provoked high dynamic loads on the plug. Morita et al. [9] studied the flow instability around a similar mushroom-type valve head at the medium opening condition using experiments and CFD simulations (large eddy simulation with modified Smagorinsky model). Asymmetric detached jet flow around the valve head was observed, and it caused rotating pressure oscillation on the valve head in all considered cases. The most profound peak was found at the low-frequency range (around $100 \mathrm{~Hz}$ ) of the pressure spectrum. The location of the peaks moved to the lower frequencies as the valve opening increased. In particular, the peaks, at around $5 \mathrm{kHz}$ in the pressure spectrum, were deemed to be caused by the acoustic resonance due to the supersonic flow around the valve head. Clari et al. [10], Engeda [11] and Bolin and Engeda [12] assessed the flow performance in the valve with a flattened valve head. They suggested that the modified design makes the flow downstream more symmetric than the mushroom-like plug. 
Pavel and Václav [13] used the PIV system to study flow structures downstream the steam turbine valve throttle. They reported the state of the jet from the throttle was historically depended and valve opening dependent. Yonezawa et al. published several articles, refers to [14-18], on the investigations of vibration behaviours and flow performance in a venturi valve using experiment facilities and CFD simulations. The jet separation around the valve head triggered stem vibration. In particular, the vibration became self-excited once the amplitude was sufficiently large because of the strong coupling of the flow instability and stem vibration in this scenario. Based on CFD investigations, Domnick et al. [19-23] identified that where the jet flow attached to the valve seat there was a sudden drop in the flow induced vibration. They related the observed re-attachment to the Coanda effect and as such, they suggested that the curvature of the valve seat should be small in order to increase the possibility for this phenomenon to manifest. In particular, it was pointed out that the extreme fine time step in the order of $10^{-6} \mathrm{~S}$ is required to capture the peak in the frequency domain of the unsteady fluid force, whilst the improper time step leads to the failure in predicting the dominant frequency of the unsteady force $[19,21]$.

At sufficiently large pressure ratios (of valve inlet to outlet pressure), the flow becomes sonic in the converging area formed by the plug and seat. The flow is further accelerated in the subsequent divergent section and becomes supersonic, and so shockwaves are formed around the valve head. These shocks cause strong unsteady forces on the valve head, which may cause chattering of the valve once the pressure wave transport at the multiple values of the natural frequency of the valve. Experimental studies showed that the fluctuating fluid thrusts on the valve head produced discrete frequencies of high level in the spectra and resulted in the forced vibration of the valve stem [24-27]. The flow separation caused by the shock-wave/boundarylayer interactions was deemed to be the major reason. Beune et al. [28] applied the 2D Unsteady RANS with Transitional turbulence of the SST model in Ansys CFX to investigate the fluidstructure-interaction in a high-pressure safety valve. Their investigation revealed the existence of the oscillatory supersonic flow and bow shocks around the valve head, as the result of highpressure ratio and small opening. It was also approved in the work by Dempster and Elmayyah, that the 2D CFD model was sufficient to provide adequate prediction of the mass flow rate of a safety valve $[29,30]$. In the numerical and experimental investigation of the safety valve performance in [31], the RANS CFD model accurately predicted the thrust on the valve head.

The aim of this paper is to understand the impact of unstable fluid excitation on the spindle in a high-pressure valve. Effects of the valve opening on the unsteady fluid force and related flow mechanisms have also been studied. The configuration considered in the current study is similar to the mode valve tested in [26]. The methodology adopted in the present work is illustrated in Figure 1. A description of the flow domain, turbulence modelling and numerical methods used is provided in Section 2. Details of a mesh independence study and validation against experimental results are provided in Section 3. Following this an assessment of unsteady forces on the valve head and the surrounding flow field is provided in Section 4 for four valve positions. Finally, the findings are summarised in Section 5. 


\section{Descriptions and Methodologies}

\subsection{Computational domain}

The computational domain was set up to match the experimental test facility used by [26], as shown in Figure 2. During their experiment, high-pressure air at room temperature was released from a tank, flowed through the converging diffuser and inlet pipe, passed the throttle formed by the seat and spindle and was finally discharged to the atmosphere. A schematic view of the CFD model domain used in the present study is shown in Figure 3. Due to the unsteady nature of the flow, the presence of multiple shockwaves and the importance of sufficient resolution of near-wall effects, the computational cost of undertaking a full 3D study is significant and beyond the resources available for this project. Since an axisymmetric segment of less than $180^{\circ}$ would be insufficient to capture the side-to-side switching of the flow, which is fundamental in the mechanism behind the flow induced vibrations, we instead opted for a $2 \mathrm{D}$ planar domain. It is important to note this is not strictly equivalent to the $3 \mathrm{D}$ geometry tested experimentally. However, since our objective focussed on demonstrating the potential of the numerical framework to capture the primary physics of shockwave-wall interactions and the side-to-side shedding mode, a 2D model is sufficient for this purpose and the indeed the success of the following results offers potential to provide insight into a complex flow mechanism at a practical cost- which we consider to be an important finding for industrial CFD users.

Similar to the experimental study, the high-pressure air flows from the inlet of the small pipe, with the diameter $(d)$ of $0.01 \mathrm{~m}$ and length $(l)$ of $0.1 \mathrm{~m}$. The spindle, with the conical valve head facing the incoming flow, is mounted in the centre of the downstream chamber. The angle of the valve head $(\mu)$ is $100^{\circ}$ while the diameter of the spindle $(D 1)$ is $0.02 \mathrm{~m}$. The diameter $(D 2)$ and length $(L)$ of the chamber are $0.06 \mathrm{~m}$ and $0.088 \mathrm{~m}$, respectively. The lift of the spindle $(h)$ is related to the valve opening ratio $(\beta)$ via Equation (1). The walls and surfaces of the testing facility are treated as smooth, isothermal and stationary.

$$
h=\frac{d}{\sin \mu}\left\{1-\sqrt{1-\beta \cos \frac{\mu}{2}}\right\}
$$

\subsection{Description of CFD models}

\subsubsection{Turbulence modelling}

The selection of turbulence model is dependent on the specific flow features for the case in question. In the current study the flow is fully turbulent flow and contains both transient flow separation and shock-wave/boundary-layer interactions both of which will require a lowReynolds near-wall modelling capability. The $k-\omega-S S T$, proposed by Menter [34], is an appropriate choice for this case particularly since the flow is $2 \mathrm{D}$, since it has a proven ability $\mathrm{o}$ to capture flow separation and lambda shock formation [35] in 2D cases. Furthermore, this choice over other candidate 2-equation models would appear not to be a significant source of doubt- based on the conclusions of a recent study on a similar 2D geometry where the six different 2-equation models tested all returned relatively similar results [32,33]. More complex 
modelling would be required for fully $3 \mathrm{D}$ internal flows with boundary layer separation, as demonstrated in recent work where a recently developed Reynolds stress transport model was tested [36]. The same study confirmed suitability of the SST model for 2D flows but demonstrated a need for more complex modelling where 3D flow effects were dominant. The advantages of a full Reynolds stress transport model can in some cases be offset by increased computational cost and reduced convergence and so other models have been proposed which aim to provide some physical advantages without the practical drawbacks (see e.g. [37]). Given the scope and objectives of the present study, the standard $k-\omega-S S T$ will be used. For completeness and since small differences in the implementation of any model can lead to slightly different results from one code the next, we have included the full model equations in Appendix I.

\subsubsection{Meshes and Cases}

The 2D flow domain is discretized using an unstructured quadrilateral mesh based on octree refinement, in order to retain a simple meshing strategy of the nature likely to be employed for common industrial CFD analysis. Figure 4 shows a view of the mesh. As depicted in the figure, scaled mesh 'prism layers' are located near the wall. The total height of the near-wall mesh layer is fixed as $1.0 \times 10^{-4} \mathrm{~m}$. Since unstable shockwaves are expected in the vicinity of the valve head, the mesh in this area is refined to capture the rapid change of variables. Such region is referred to herein as the 'focus area'. A relatively coarse mesh is retained in the so-called 'general area'. The transfer between the fine mesh and coarse mesh is achieved by gradually reducing the mesh size. The effect of different mesh configurations is firstly examined before further discussions. In general two factors have been studied; the resolution of the near-wall mesh and the mesh size away from the wall. The details of the studied meshes are documented in Table 1. The near wall mesh is gradually refined by increasing the number of prism layers and reducing the stretch ratios in meshes 'MSH-1, 2, and 3', while other settings are kept the same. The Mesh denoted 'MSH-2A' is a coarsened version of 'MSH-2', as the base element dimension was halved, however, the resolutions in the near-wall regions of both are similar.

Table 1 Detail of meshes:

\begin{tabular}{|c|c|c|c|c|c|}
\hline \multirow{2}{*}{ Meshes } & element size (m) & $\begin{array}{l}\text { Near wall } \\
\text { mesh }\end{array}$ & $\begin{array}{l}\text { Near wall mesh } \\
\text { stretch ratio }\end{array}$ & $\begin{array}{l}\text { Height of } 1 \text { st near } \\
\text { wall mesh }(\mathrm{m})\end{array}$ & \multirow{2}{*}{$\begin{array}{l}\text { Total number } \\
\text { of cells }\end{array}$} \\
\hline & $\begin{array}{l}\text { General area/ } \\
\text { Focus area }\end{array}$ & layers & $\begin{array}{l}\text { General area/ } \\
\text { Focus area }\end{array}$ & $\begin{array}{l}\text { General area/ } \\
\text { Focus area }\end{array}$ & \\
\hline MSH-1 & $2.5 \mathrm{e}-04 / 6.5 \mathrm{e}-05$ & 10 & $1.35 / 1.6$ & $9.16 \mathrm{e}-07 / 2.75 \mathrm{e}-07$ & $257 \mathrm{k}$ \\
\hline MSH-2 & $2.5 \mathrm{e}-04 / 6.5 \mathrm{e}-05$ & 15 & $1.2 / 1.4$ & 7.0e-07/1.3e-07 & $277 \mathrm{k}$ \\
\hline MSH-3 & $2.5 \mathrm{e}-04 / 6.5 \mathrm{e}-05$ & 20 & $1.15 / 1.25$ & $4.88 \mathrm{e}-07 / 1.46 \mathrm{e}-07$ & $297 \mathrm{k}$ \\
\hline MSH-2A & $5.0 \mathrm{e}-04 / 1.25 \mathrm{e}-04$ & 15 & $1.2 / 1.4$ & 7.0e-07/1.3e-07 & $87.2 \mathrm{k}$ \\
\hline
\end{tabular}

Since the pressure-velocity coupled flow solver is utilised, the shock waves can be computed as a part of the solutions of the CFD model. Hence, no extra shock-capturing scheme is applied. The convection terms in the momentum and transport equations for turbulence 
quantities are discretized using the second-order upwind difference scheme. The interval of the time step, in the CFD model, is set to $5 \times 10^{-8} \mathrm{~s}$ which ensures the CFL number smaller than 0.65 in all of the numerical models, while the temporal discretization scheme is set to $2^{\text {nd }}$ order.

For the purpose of the mesh independence study, the value of $\beta$ is set to 0.5 . Having identified a suitable mesh for the validation case, three additional meshes are generated to provide a set of CFD models for the other three valve opening ratios $\beta=\{0.25,0.75,1.0\}$. In all of the CFD models, the pressures at inlet and outlet are $0.8 \mathrm{MPa}$ and $0.1 \mathrm{MPa}$, respectively. The properties of the compressible air at room temperature is governed by the ideal gas model as:

$$
\rho=\frac{P_{a b s}}{R T}
$$

where $T$ is the temperature and $P_{a b s}$ and $R$ are the absolute pressure and specific gas constant, which are defined as:

$$
\begin{gathered}
P_{a b s}=P_{\text {static }}+P_{\text {ref }} \\
R=R_{u} / M
\end{gathered}
$$

where $R_{u}$ is the universal constant $(8314.4621 \mathrm{~J} / \mathrm{kmol} \cdot \mathrm{K})$ and $M$ is the molecular weight of air $(28.9664 \mathrm{~kg} / \mathrm{kmol})$.

\section{Validation of Methodology}

\subsection{Mesh Sensitivity Study and Validation of the CFD model}

\subsubsection{Mesh sensitivity study}

Several locations are defined around the valve head, as shown in Figure 5, to extract the local profiles of relevant flow variables from the domain. Profiles of time-averaged velocity and turbulent kinetic energy, are provided in Figure 6, wherein the convergence of the mesh is clearly demonstrated. Considering first the velocity profiles on the Lines $0-4$, Figure $6(\mathrm{a})$, the development of the supersonic flow around the valve head is captured by the meshes. In particular, the prediction of velocity near to the wall is improved with the subsequent refinement of the near wall mesh. The inconsistency between the predictions of the velocity, by the models using MSH-1 and MSH-2, in the near-wall region grows as the flow moves towards the tail of the conical valve head. In the region away from the wall, the difference between the results of these two meshes can also be seen as the supersonic jet being developing. In contrast, the numerical predictions using meshes, MSH-2 and MSH-3, almost overlap with each other. The difference between the results by MSH-2A and their counterparts, MSH-2, lies in the transient region between the subsonic flow and supersonic flow. Considering that the number of mesh elements in MSH-2 is around four times than that of MSH-2A, the improvement due to the refinement of the mesh away from the wall is deemed to be small. Similar observations can also be found in the predictions of turbulence kinetic energy, as presented in Figure 6(b). The near-wall refinement plays an important role not just in capturing 
the peak values of the turbulent kinetic energy in the near wall region, but also subsequently in its transportation away from the wall. The inconsistency between the predictions of turbulence kinetic energy using MSH-1 and MSH-2 starts to appear on the Line1, which is earlier than the discrepancy observed in the velocity profiles. The differences between the values predicted by MSH-2 and MSH-3 can be seen in the figure, however, the magnitude is small and acceptable, similar to the inconstancy between the results by MSH-2 and MSH-2A. In conclusion, it is reasonable to state that a satisfactory level of mesh independence has been achieved with MSH2 and as such this mesh is used in the subsequent study.

\subsubsection{Validation of CFD model}

To further demonstrate the suitability of the CFD model, the predictions obtained using MSH2 are compared to the experimental observations of the half-opened valve with similar operating conditions $\left(\mathrm{P}_{\text {out }}=0.1 \mathrm{MPa}\right.$ and $\left.\mathrm{P}_{\text {out }}=0.8 \mathrm{MPa}\right)$. In terms of the flow domain, a marked similarity is demonstrated between the observation and the numerical simulation, as seen in Figure 7. The shock pattern appears to be well captured by the CFD model. The axial force is evaluated as the production of the cross-sectional area of the valve head in the axial direction and the pressure difference between the pressure on the valve head and atmosphere pressure $(0.1 \mathrm{MPa})$. The spectra of the measured and predicted axial forces, on the valve head, are compared in Figure 8. The arrows in the experimental waterfall spectra plot (left of Figure 8) indicate the frequency peaks in the spectrum of axial oscillating fluid force. These frequency peaks are also observed in the numerical output. Particularly, the profound peak at around 8 $\mathrm{kHz}$ and its second harmonics $(\sim 16 \mathrm{kHz})$ are captured by the numerical simulation even with similar amplitudes to the experimental data. It suggests that despite the $2 \mathrm{D}$ planar approximation made in this case, the CFD model is able to reproduce the flow domain as well as the oscillating fluid force on the spindle.

\section{Investigation into different valve position.}

\subsection{Oscillating Fluid Force and Unsteady Flows}

\subsubsection{Instantaneous performance of unsteady dynamic forces}

In the present work, our discussion focuses on the transient axial loading on the valve head, which has been identified as the principal cause for the damage identified in similar valves in operational use. The instantaneous axial fluid forces on the spindle are plotted in Figure 9 for the different opening ratios. As expected, a strong unsteady force is present in all cases. Interestingly, low-frequency modulations are observed in the signals. Compared to results of $\beta$ $=0.5$ and 0.75 , the signal modulations in the cases of $\beta=0.25$ and 1.0 are more visible. As displayed in Figure 10(a), the time-averaged force decreases linearly with the lift of the valve head. The value in the case of the fully opened valve $(\beta=1.0)$ is around $75 \%$ of the same quantity in the $25 \%$ opened case. The r.m.s. of the fluctuating component, $f^{\prime \prime}(t)$, of the force, 
$F(t)$, is presented in Figure 10(b). This quantity is observed to increase by almost $100 \%$ as $\beta$ increases from 0.25 to 0.5 . It then decreases in the cases of $\beta=0.75$ and 1.0 , although it is noted to remain significantly higher in the 0.75 case than in the 0.25 case. On the basis of this observation is seems that substantially more fatigue damage may be expected when the valve opening ranges from $50 \%$ to $75 \%$ open.

A spectral analysis of the forces is carried out to further elucidate the dynamic response to unsteady flows. The averaged spectra are computed for time domain force signals. Each signal is divided into 7 equal segments of size $0.0131 \mathrm{~s}$ (contains $2^{18}$ samples) with a 50\% overlap. The spectra from these segments are then averaged in order to reduce the noise level. The frequency resolution of the results is $0.076 \mathrm{kHz}$. Figure 11 shows the spectra of the oscillating forces for different $\beta$. In the case of $\beta=0.25$, multiple peaks present across a wide range of frequencies; clearly undesirable since this represents an increased likelihood that one or more of these frequencies may be close to the spindle or the valve natural frequency. The number of frequency peaks in the force spectrum is observed to reduce as the valve is opened from $\beta=$ 0.25 to 1 . Similarly, this indicates favourable operating conditions and reduced risk of dynamic mode correspondence with resonant frequencies of the structure. The most significant peaks in the force spectra in the $\beta=0.25$ case are predicted to be located at $7.5 \mathrm{kHz}$ and $8.0 \mathrm{kHz}$. The magnitude of the peak at $7.5 \mathrm{kHz}$ reduces as the opening ratio increase, while the peak at 8.0 $\mathrm{kHz}$ disappears altogether as $\beta$ increases to 0.75 and 1.0 ; only the peak at $7.5 \mathrm{kHz}$ remains. Furthermore, the trend in the amplitude of these dominant peaks amplitudes echoes the prior observation in the r.m.s. of the $f^{\prime \prime}(t)$.

\subsubsection{Time-averaged flow domain}

The long-time averaged velocity fields and pressure fields are illustrated in Figure 12. In view of the near-symmetrical nature of these results, only one half of the domain are shown to save space. As expected, the flow is greatly accelerated just after the throttle formed by the seat and plug and a supersonic jet is formed around the valve head. As $\beta=0.25$, the maximum velocity ( $2 \mathrm{Ma}$ ) can be observed in the region close to the throttle. It is then quickly reduced. The location of the maximum velocity is observed to move towards the tail of the valve head as the valve opens. Except for the case of $\beta=0.25$, the time-averaged supersonic jet is not always attached to the valve head. The separation occurs at the point of deceleration. The point of the flow separation moves downstream with the high-velocity region of the flow. It is also interesting to note that the flow tends to re-accelerate in the region away from the plug when the valve is largely opened, i.e. for $\beta=0.75$ and 1.0. Furthermore, the width of the supersonic jet increases with the valve opening ratio.

The pressure field is presented in Figure 12. In general, the discrete pressure distributions can be observed around the valve head in all cases. A low-pressure patch appears around the valve head as a result of the flow acceleration. The lowest pressure region shown in the figure overlaps at the location of maximum velocity region. Subsequently, a relatively high-pressure region is formed on the plug surface before it decreases again. In the fully opened valve case, 
the low-pressure region can be observed in the region away from the valve. The existence of such a low-pressure region can be used to explain the observed region of flow acceleration.

The average pressure on the conical valve head is illustrated in Figure 13(a), where it is observed to recover slightly after the initial rapid decrease, before decreasing further in the cases. The amplitude of the wavy distribution of $\mathrm{P} / \mathrm{P}_{\text {out }}$ becomes smaller as the opening is increased and disappears once the valve is fully opened. To understand the flow phenomenon close to the valve head surface, Figure 13(b) shows the averaged friction velocity $\left(\left\langle u_{\tau}\right\rangle\right)$ on the conical valve head. It should be noted here the $u_{\tau}$ is a scalar, calculated from the magnitude of the wall shear stress. As the flow passes the valve head, the $\left\langle u_{\tau}\right\rangle$ initially increases, followed by a rapid decrease. The rise and fall of $\left\langle u_{\tau}\right\rangle$ along the valve head indicates the existence of shocks around the valve head. The location of the peak moves towards the end of the valve head as the opening increases, which implies the foot of the shock moves due to the movements of the stem. Interestingly, a second peak appears on the profile of $\left\langle\boldsymbol{u}_{\tau}\right\rangle$ in the case of $\beta=0.25$, which implies that more than one static shock is present on the valve head in this case.

Due to strong shear formed between the supersonic jet and subsonic flow region, a high level of turbulent kinetic energy is expected, as shown in Figure 14. These elevated levels of turbulence act to reduce rotational content in the flow as a consequence of a corresponding increase in turbulent viscosity. In order to more directly compare the mean flow structures in the valve with different opening ratios, streamlines are computed from the time-averaged velocity field and illustrated in Figure 15. In all cases the jet flow emanating from the throttle changes direction once it hits the wall of the chamber, at which point flow recirculation is formed on both sides of the jet. The corners of the chamber are dominated by large flow recirculation in all cases. It is noted that the flow recirculation is anticipated to be stronger in the $2 \mathrm{D}$ case studied here than would be the case for a $3 \mathrm{D}$ flow. Smaller flow recirculation is observed close to the throttle and in the corner for $\beta=0.25$, disappears for $\beta=0.5$ and 0.75 and re-emerges in the fully opened valve. This may indicate the violent unsteadiness of the flow around the valve head as the opening is $50 \%$ or $75 \%$. Furthermore, the strong flow recirculation away from the valve head disappears in the case for $\beta=1$.0. And, the flow recirculation close to the spindle was greatly stretched for $\beta=1.0$.

\subsubsection{Instantaneous flow domain}

To further understand the origins of the oscillating dynamic force on the valve head, the unsteady flow field is now discussed. The instantaneous pressure fields together with the Schlieren plots of the flow domain are displayed in Figure 16, while instantaneous behaviours of large scale flow structures are presented in Figure 17. The supersonic jet around the valve head creates the rapid density changes between the fluid in and out of the jet. The high level of density gradient is used to indicate the boundary of the supersonic jet as well as the existence of the shocks. 
Figure 16 provides a series of snapshots which illustrate the evolution of unsteady features of the supersonic jet around the valve and the associated shock trains. The boundary of the jet flow continuously changes with the expansion and shrink of the low-pressure region around the valve head. These flow behaviours are similar to the supersonic jet from the nozzle and can be explained by the following mechanisms. As the compressible fluid leaves the throttle, it expands and forms the rarefaction fans (the dark region at the sharp corner of the seat). The fluid tends to over expand, while the fluids outside the supersonic jet with higher pressure push it towards the valve head. Meanwhile a shock forms at the valve head and travels towards the jet boundary, leading to a reflected shock which may again trigger another shock at the other side of the jet flow. This process repeats over and over and forms a train of shocks, eventually dissapearing as the jet flow becomes subsonic. The unsteady forwards/backwards motion of the first shock gives rise to unsteadiness throughout the rest of the shock train.

In the case of $\beta=0.25,0.5$. multiple shocks are observed to impinge on the valve head, as shown in Figure 16(a). At greater opening ratios, the reflected shocks are less likely to land on the valve head because the shocks must travel further before being reflected. Flow separation due to the foot of the first shock can introduce more unsteadiness to the pressure field, although for the lower opening ratios, the momentum appears to be sufficient to reattach such separations. This is not the case for the larger opening ratios where the supersonic jet detaches and oscillates freely, giving rise to stronger fluid force oscillations in these two cases $(\beta=0.5$ and 0.75$)$. In the case of the fully opened valve $(\beta=1.0)$, the foot of the shock is more likely to appear at the tail of the conical valve head and there are thus no reflected shocks on the valve head, and the normal force is reduced accordingly.

The plots in Figure 17 describe the transient evolution of the velocity streamlines for each case. Recirculating flow is generated in the vicinity of the jet giving rise to an unsteady flow recirculation. Significant unsteadiness is observed to form at the internal corners above and below the valve head for the $50 \%$ and $75 \%$ cases, when compared to the other two cases, emphasising similar observations from earlier figures. The subsequent unsteadiness of the downstream flow in these cases will induce an unsteady pressure field around the stem, thereby increasing the unsteady force in the normal direction. In such cases the impact of the unsteady downstream flow could be mitigated with the introduction of a barrier or 'guide' around the stem itself.

\section{Conclusions}

The unsteady flow through a high-pressure valve has been computed for four different valve opening ratios and the flow field and associated fluid loading on the spindle has been analysed in detail. This study provides validation that an industry standard 2D unsteady RANS model is able to provide insight to the shockwave formation and associated unsteady force on the valve head with reasonable correspondence to experimental measurements. 
The spectral bandwidth of the unsteady loading on the spindle is observed to increase when the valve is partially opened. While the study does not compute the structural response of the valve to the fluid, this finding indicates an increased likelihood of triggering harmonic structural vibrations in a partially opened valve, especially in the case of $25 \%$ opening. Accordingly even stronger spindle vibration is expected in the valve when the opening is between $50 \%$ and $75 \%$, due to the larger amplitude of unsteady fluid force predicted to act on the spindle in these cases. As a result of these findings it is reasonable to conclude that long-term plant operation of a valve in similar flow conditions with an opening ratio in the range of $50 \%$ to $75 \%$ is likely to be subject to substantially more fatigue damage in the valve components than for $100 \%$ open case.

Analysis of the results identifies that the observed unsteadiness of the fluid force acting on the valve is associated with the prominence of two features; shock-wave/boundary-layer interactions and flow separation. Shock-wave/boundary-layer interactions produce unsteadiness of the shock system and causes significant pressure oscillation. Where shockwave/boundary-layer interactions occur, they induced flow separation at the wall. When the valve opening is small and the momentum is high, the separated jet flow is likely to be reattached to the valve head. As the opening ratio increases, the shock system moves towards the downstream location due to the increasing gap between the valve head and the expansion point. In the meantime, the separation due to shock-wave/boundary-layer interaction grow in size and after a certain point, the flow is no longer able to reattach. At the point at which the flow becomes detached from the valve head, the supersonic jet becomes increasingly unstable, giving rise to significant pressure oscillation and broad spectral axial forcing, e.g. 50\% and 75\% open case. As the valve opens further, the shock moves to towards the tail of the conical valve, and as such the region of flow separation, and thus unsteady loading along the valve head is reduced.

The current work is limited to a simplified 2D approximation of the valve, and flow unsteadiness may be overpredicted due to the enhanced coherence of rotational flow in this case. Further work is required to examine the fully $3 \mathrm{D}$ flow field to investigate the role of circumferential instabilities on the valve loading.

\section{Acknowledgements}

This work is funded by the Innovate UK and EDF Energy UK via the Knowledge Transfer Partnership (KTP) program. 


\section{Appendix I}

The full details of the $k-\omega-S S T$ model used in this study are given below for clarity, following the implementation guide from Star-CCM+10.04:

$$
\begin{gathered}
\frac{\partial(\rho k)}{\partial t}+\frac{\partial\left(\rho k u_{j}\right)}{\partial u_{j}}=\frac{\partial}{\partial x_{j}}\left[\left(\mu+\sigma_{k} \mu_{t}\right) \frac{\partial k}{\partial x_{j}}\right]+G_{k}-\gamma^{\prime} \rho \beta_{c o m p}^{*} f_{\beta^{*}} \omega k \\
\frac{\partial(\rho \omega)}{\partial t}+\frac{\partial\left(\rho \omega u_{j}\right)}{\partial u_{j}}=\frac{\partial}{\partial x_{j}}\left[\left(\mu+\sigma_{\omega} \mu_{t}\right) \frac{\partial \omega}{\partial x_{j}}\right]+G_{\omega}-\rho \beta_{c o m p} f_{\beta} \omega^{2} k+D_{\omega}
\end{gathered}
$$

where the production terms $G_{k}, G_{\omega}$ and cross-derivative term $D_{\omega}$ are defined as follows:

$$
\begin{gathered}
G_{k}=\mu_{t} f_{c} S^{2}-\frac{2}{3} \rho k(\nabla \cdot \vec{u})-\frac{2}{3} \mu_{t}(\nabla \cdot \vec{u})^{2} \\
G_{\omega}=\rho \gamma\left[\left(S^{2}-\frac{2}{3}(\nabla \cdot \vec{u})^{2}\right)-\frac{2}{3} \omega(\nabla \cdot \vec{u})\right] \\
D_{\omega}=2\left(1-F_{1}\right) \frac{\rho \sigma_{\omega 2}}{\omega} \frac{\partial k}{\partial x_{j}} \frac{\partial \omega}{\partial x_{j}}
\end{gathered}
$$

The turbulent viscosity is defined as $\mu_{t}=\rho k T$, where the turbulent time scale $\mathrm{T}$ is computed using Durbin's realizability constant as:

The $F_{2}$ is defined as

$$
T=\min \left(\frac{1}{\max \left(\omega / \alpha^{*}, S F_{2} / a_{1}\right)}, \frac{C_{T}}{\sqrt{3} S}\right)
$$

$$
F_{2}=\tanh \left(\left(\max \left(\frac{2 \sqrt{k}}{\beta_{c o m p}^{*} \omega y}, \frac{500 v}{y^{2} \omega}\right)\right)^{2}\right)
$$

, while $a_{1}$ and $C_{T}$ are 0.31 and 0.6 respectively. The coefficient $\beta_{\text {comp }}^{*}$ and $\beta_{\text {comp }}$ are calculated by using following equations:

$$
\begin{gathered}
\beta_{\text {comp }}^{*}=\beta^{*}\left[1+\xi^{*} F\left(M_{t}\right)\right] \\
\beta_{\text {comp }}=\beta-\beta^{*} \xi^{*} F\left(M_{t}\right) \\
F\left(M_{t}\right)=\max \left(0, M_{t}^{2}-M_{t 0}^{2}\right) \\
M_{t}^{2}=\frac{2 k}{a^{2}} \text { and } M_{t 0}=\frac{1}{4}(a \text { is the speed of sound })
\end{gathered}
$$

The $\beta^{*}=0.09$, while the $\beta$ and other coefficients, such as $\sigma_{k}, \sigma_{\omega}$, and $\gamma$ in the model are calculated from the blending function $F_{1}$. A general expression of $\varphi$, representing the corresponding constant (e.g. $\beta, \sigma_{k}, \sigma_{\omega}$, and $\gamma$ ) in the model, is given by:

$$
\varphi=F_{1} \varphi_{1}+\left(1-F_{1}\right) \varphi_{2}
$$

In Eq. (13), The $\varphi_{1}$ represents constants such as $\beta_{1}=0.075, \sigma_{k 1}=0.85, \sigma_{\omega 1}=0.5$, or $\gamma_{1}=$ $\left(\beta_{1} / \beta^{*}\right)-\sigma_{\omega 1}\left(\kappa^{2} / \sqrt{\beta^{*}}\right)$. Meanwhile, the $\varphi_{2}$ represents $\beta_{2}=0.0828, \sigma_{k 2}=1.0, \sigma_{\omega 1}=0.856$, or $\gamma_{2}=\left(\beta_{2} / \beta^{*}\right)-\sigma_{\omega 2}\left(\kappa^{2} / \sqrt{\beta^{*}}\right)$. The $\kappa$ is the von Karman constant and equals to 0.41 .

The $F_{l}$ in Eq. (13) is defined as 


$$
\begin{gathered}
F_{1}=\tanh \left(\left(\min \left(\max \left(\frac{2 \sqrt{k}}{\beta^{*} \omega y}, \frac{500 v}{y^{2} \omega}\right), \frac{2 k}{y^{2} C D_{k \omega}}\right)\right)^{4}\right) \\
C D_{k \omega}=\max \left(\left(\frac{1}{\omega} \frac{\partial k}{\partial x_{j}} \frac{\partial \omega}{\partial x_{i}}\right), 10^{-20}\right)
\end{gathered}
$$

\section{References:}

[1] A.E. Zaryankin, N.A. Zroichikov, A.N. Paramonov, V. V Noskov, E.Y. Grigor, Pressure pulsations in the turbine steam admission path and their influence on the vibration state of the turbine control valves, Therm. Eng. 59 (2012) 106-112. doi:10.1134/S0040601512020176.

[2] V.F. Kasilov, S. V. Kalinin, V.M. Gvozdev, V.S. Kartashov, E.M. Emel'yanov, A study of the vibrational activity of the control valves in the steam addmission system of the HP cylinder in a K-200-130 Turbine, Therm. Eng. 48 (2001) 890-898.

[3] V.G. Orlik, Y.E. Minenkov, Effect of self-excited vibrations of regulating valves of a steam turbine on the vibration state of the rotor, Power Technol. Eng. 38 (2004) 275278.

[4] P. Kollross, Introduction to Flow Instability in Turbine Control Valve, AIP Conf. Proc. 1889 (2017). doi:10.1063/1.5004356.

[5] T. Araki, Y. Okamoto, F. Ootomo, Fluid-induced vibration of steam control valves, Toshiba Rev. 36 (1981) 648-656.

[6] D. Zhang, A. Engeda, Venturi valves for steam turbines and improved design considerations, Proc. Instn Mech. Engrs, Part A J. Power Energy. 217 (2003) 219-230.

[7] D. Zhang, A. Engeda, J.R. Hardin, R.H. Aungier, Experimental study of steam turbine control valves, Proc. Inst. Mech. Eng. Part C J. Mech. Eng. Sci. 218 (2004) 493-507. doi:10.1243/095440604323052283.

[8] J. Hardin, F. Kushner, S. Koester, Elimination of flow-induced instability from steam turbine control valves, in: 32nd Turbomach. Symp. Turbomach. Lab. Texas A\&M Univ. Coll. Station. Texas, USA, 2003: pp. 99-108.

[9] R. Morita, F. Inada, M. Mori, K. Tezuka, Y. Tsujimoto, CFD Simulations and Experiments of Flow Fluctuations Around a Steam Control Valve, J. Fluids Eng. 129 (2007) 48. doi:10.1115/1.2375123.

[10] M.B. Clari, T. Polklas, F. Joos, Three-Dimensional Flow Separations in the Diffuser of a Steam Turbine Control Valve, in: ASME Turbo Expo 2011, 2011: pp. 1-8.

[11] A. Engeda, Performance Study and Instability Analysis of Steam Turbine Control Valve, in: ASME Turbo Expo 2012, ASME, 2012: p. 651. doi:10.1115/GT201268740.

[12] C. Bolin, A. Engeda, Analysis of flow-induced instability in a redesigned steam control valve, Appl. Therm. Eng. 83 (2015) 40-47.

doi:10.1016/j.applthermaleng.2015.02.043. 
[13] P. Pavel, U. Václav, Bistable flow occurrence in the 2D model of a steam turbine valve, AIP Conf. Proc. 1889 (2017). doi:10.1063/1.5004363.

[14] K. Yonezawa, Y. Toyohira, T. Nagashima, Y. Tsujimoto, K. Tezuka, M. Mori, R. Morita, F. Inada, An Experimental Study of Unsteady Transonic Flow in a Steam Control Valve with Simple Model, J. Environ. Eng. 5 (2010) 134-143. doi:10.1299/jee.5.134.

[15] K. Yonezawa, K. Ogi, T. Takino, Y. Tsujimoto, T. Endo, K. Tezuka, R. Morita, F. Inada, Experimental and numerical investigation of flow induced vibration of steam control valve, in: ASME 2010 3rd Jt. US-European FLuids Eng. Summer Meet. 8th Int. Conf. Nanochannels, Microchannels Minichannels, 2010: pp. 1-9.

[16] K. Yonezawa, R. Ogawa, K. Ogi, T. Takina, Y. Tsuijimoto, T. Endo, K. Tezuka, R. Morita, F. Inada, Flow-Induced Vibration of Valve Head of Steam Control Valve, Trans. JAPAN Soc. Mech. Eng. Ser. B. 77 (2011) 1098-1110. doi:10.1299/kikaib.77.1098.

[17] K. Yonezawa, R. Ogawa, K. Ogi, T. Takino, Y. Tsujimoto, T. Endo, K. Tezuka, R. Morita, F. Inada, Flow-induced vibration of a steam control valve, J. Fluids Struct. 35 (2012) 76-88. doi:10.1016/j.jfluidstructs.2012.06.003.

[18] K. Yonezawa, R. Ogawa, K. Ogi, T. Takino, Y. Tsujimoto, T. Endo, K. Tezuka, R. Morita, F. Inada, Flow-induced vibration of a steam control valve, J. Fluids Struct. 35 (2012) 76-88. doi:10.1016/j.jfluidstructs.2012.06.003.

[19] C.B. Domnick, F.-K. Benra, D. Brillert, H.J. Dohmen, C. Musch, Numerical Investigation on the Time-Variant Flow Field and Dynamic Forces Acting in Steam Turbine Inlet Valves, J. Eng. Gas Turbines Power. 137 (2015) 081601. doi:10.1115/1.4029309.

[20] C.B. Domnick, F. Benra, D. Brillert, H.J. Dohmen, C. Musch, Improving the design of steam turbine inlet valves by numerical methods for enhanced part load operation, in: 11th Eur. Turbomach. Conf. ETC, Madrid, Spain, 2015: pp. 1-13.

[21] C.B. Domnick, D. Brillert, C. Musch, Numerical investigation on the vibration of steam turbine inlet valves and the feedback to the dynamic flow field, in: ASME Turbo Expo 2015 Turbine Tech. Conf. Expo., 2015: pp. 1-13.

[22] C.B. Domnick, F.-K. Benra, H.J. Dohmen, C. Musch, Numerical Investigation on Under Expanded Wall Jet Separation in a Steam Turbine Valve Diffuser, in: 15th Int. Symp. Transp. Phenom. Dyn. Rotating Mach., 2014: pp. 1-10.

[23] C.B. Domnick, F.K. Bera, D. Brillert, C. Musch, Modification of a steam valve diffuser for enhanced full load and part load operation using numerical methods, Period. Polytech. Mech. Eng. 60 (2016) 185-192. doi:10.3311/PPme.9041.

[24] M. Nakano, E. Outa, K. Tajima, Aerodynamic study on noise and vibration generated in high pressure gas valves, part 1: flow patterns and noise of supersonic air flow dischaged through conical valve plugs into atmosphere, Bull. JSME. 22 (1979) 15781586.

[25] M. Nakano, K. Tajima, E. Outa, Aerodynamic study on noise and vibration generated 
in high pressure gas vlaves, part 2: fluid thrust related to flow patterns of supersonic air flow discharged through conical valve plugs into atmosphere, Bull. JSME. 26 (1983) 372-379.

[26] M. Nakano, K. Tajima, Aerodynamic study on noise and vibration generated in high pressure gas valves, part 3: noise and vibration induced by internal oscillating flow in conical plug-circullar chest valves, Bull. JSME. 27 (1984) 691-699.

[27] M. Nakano, E. Outa, K. Tajima, Noise and Vibration Related to the Patterns of Supersonic Annular Flow in a Pressure Reducing Gas Valve, J. Fluids Eng. 110 (1988) 55. doi:10.1115/1.3243511.

[28] A. Beune, J.G.M. Kuerten, M.P.C. van Heumen, CFD analysis with fluid-structure interaction of opening high-pressure safety valves, Comput. Fluids. 64 (2012) 108116. doi:10.1016/j.compfluid.2012.05.010.

[29] W.M. Dempster, W. Elmayyah, A computational fluid dynamics evaluation of a pneumatic safety relief valve, in: 13th Int. AMME Conf., 2008: pp. 27-29.

[30] W. Dempster, W. Elmayyah, Two phase discharge flow prediction in safety valves, Int. J. Press. Vessel. Pip. 110 (2013) 61-65. doi:10.1016/j.ijpvp.2013.04.023.

[31] V. Dossena, F. Marinoni, F. Bassi, N. Franchina, M. Savini, Numerical and experimental investigation on the performance of safety valves operating with different gases, Int. J. Press. Vessel. Pip. 104 (2013) 21-29. doi:10.1016/j.ijpvp.2013.01.002.

[32] Y. Duan, M.D. Eaton, M.J. Bluck, C. Jackson, A Validation of CFD Methods on Predicting Valve Performance Parameters, in: ASME 2018 Power Energy Conf. Exhib., 2018: pp. 1-10. doi:10.1115/POWER2018-7434.

[33] Y. Duan, C. Jackson, M.D. Eaton, M.J. Bluck, An assessment of eddy viscosity models on predicting performance parameters of valves, Nucl. Eng. Des. 342 (2019) 60-77. doi:10.1016/j.nucengdes.2018.11.036.

[34] F.R. Menter, Two-equation eddy-viscosity turbulence models for engineering applications, AIAA J. 32 (1994) 1598-1605. doi:10.2514/3.12149.

[35] F. Thivet, Lessons learned from RANS simulations of shock-wave/boundary-layer interactions, in: 40th AIAA Aerosp. Sci. Meet. Exhib., Reno,NV,U.S.A., 2002. doi:10.2514/6.2002-583.

[36] F. Billard, A. Revell, T. Craft, Application of recently developed elliptic blending based models to separated flows. International Journal of Heat and Fluid Flow, 35 (2012). doi: 10.1016/j.ijheatfluidflow.2012.04.012

[37] A. Revell, T. Craft, D. Laurence. Turbulence Modelling of Unsteady Turbulent Flows Using the Stress Strain Lag Model. Flow Turbulence Combust 86. (2011) doi: 10.1007/s 10494-010-9297-9 


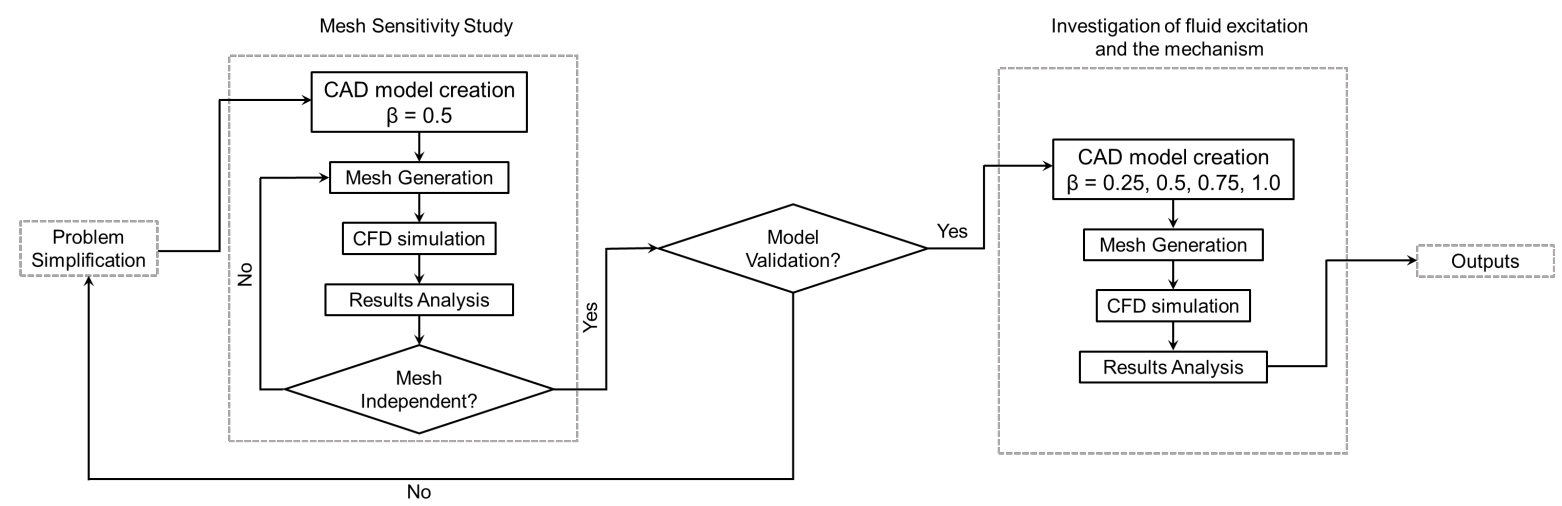

Figure 1 The diagram of the analysis approach.

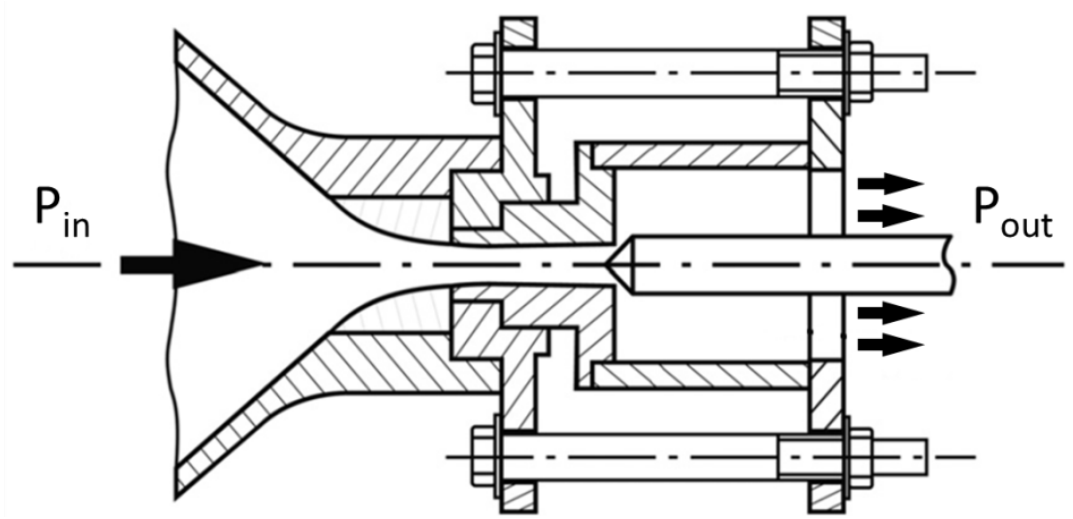

Figure 2 The mode valve tested by [26].

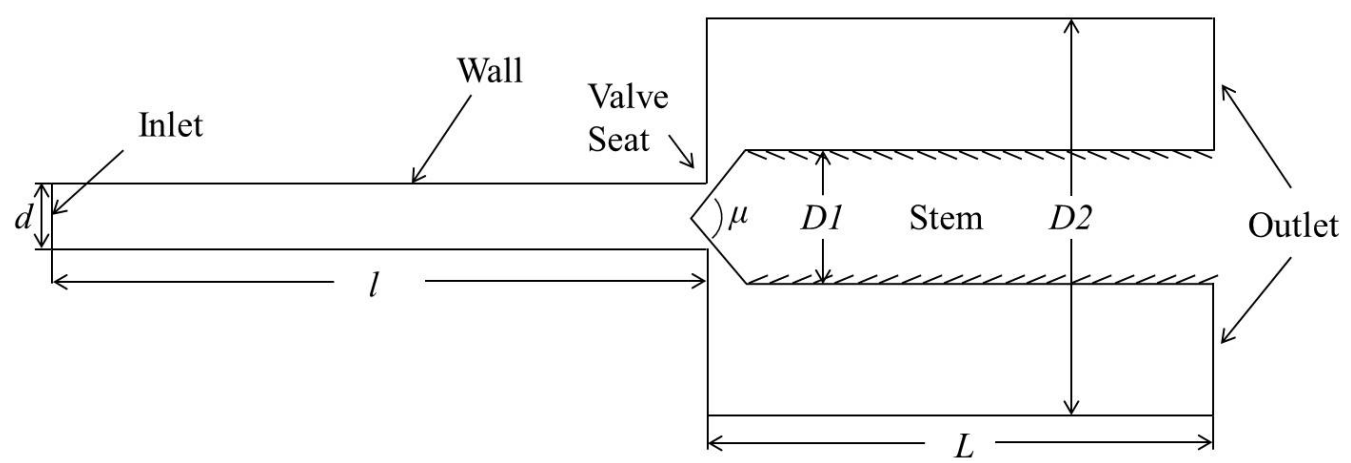

Figure 3 The 2D geometry for the CFD model. 


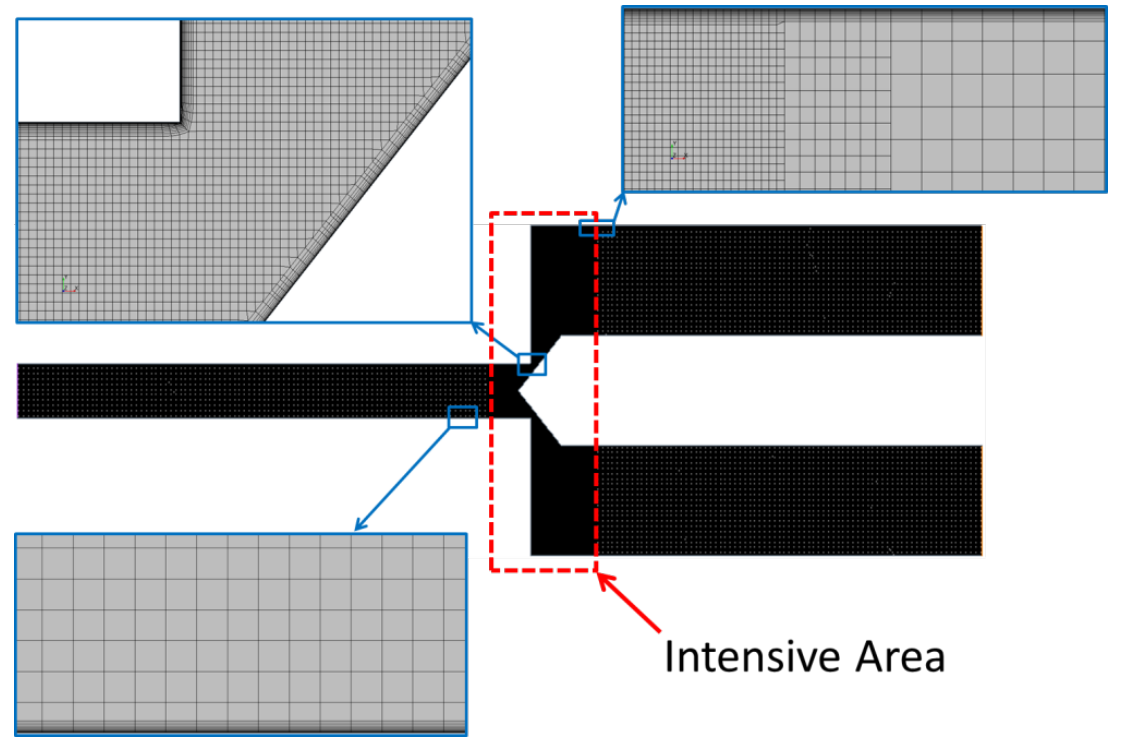

Figure 4 An overview of the mesh in the CFD model.

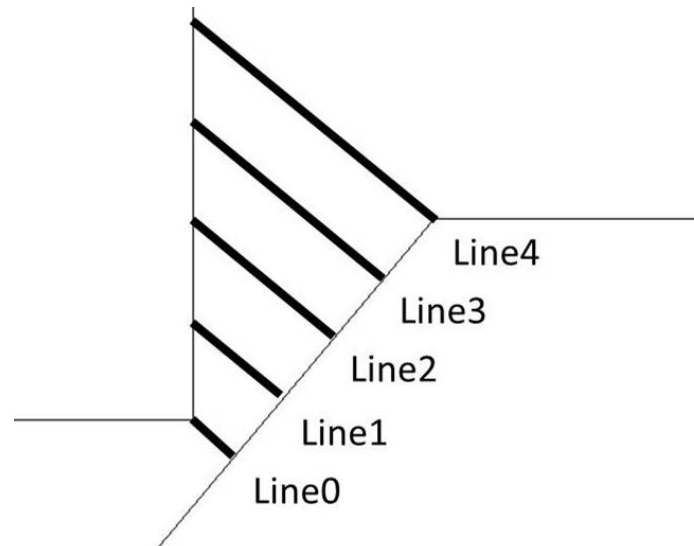

Figure 5 The lines across the region formed by the stem and seat.

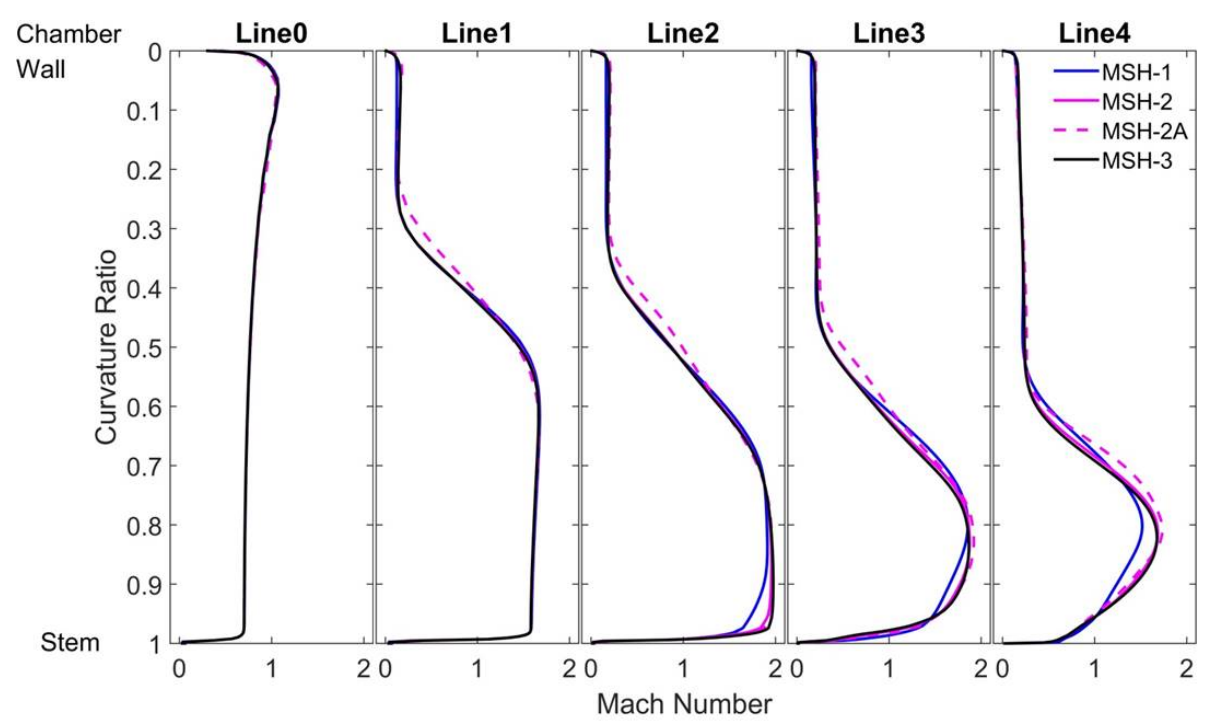

(a) 


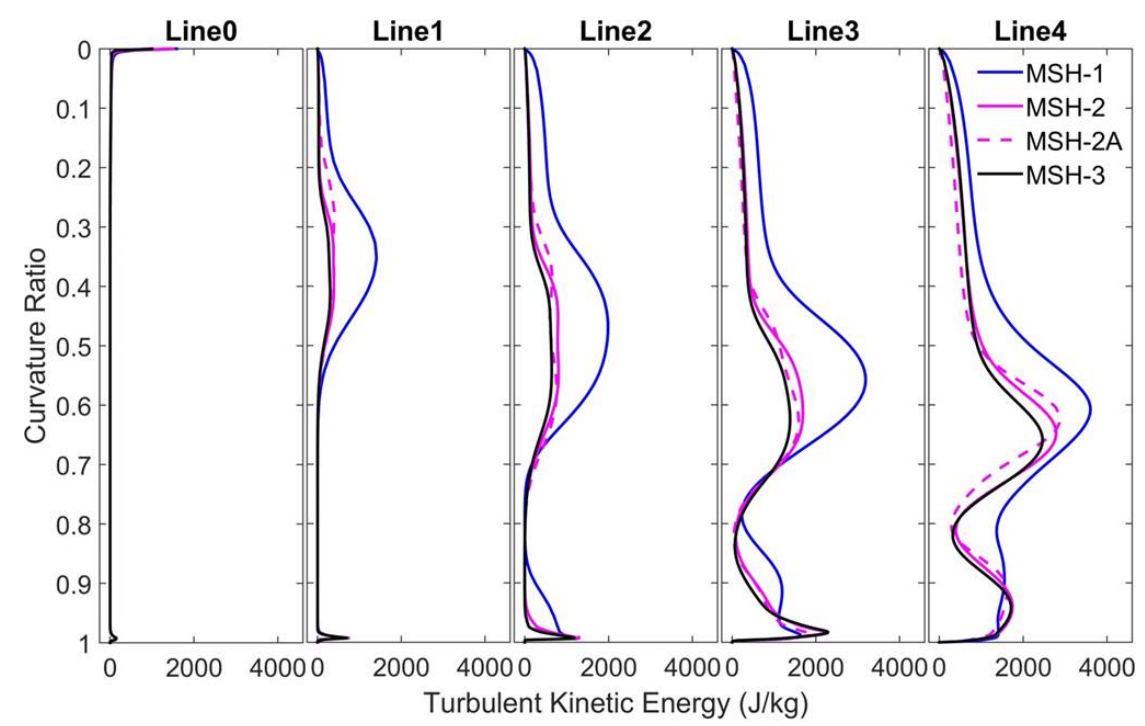

(b)

Figure 6 The numerical predictions of (a) Velocity profile and (b) turbulent kinetic energy on the lines using different mesh configurations.
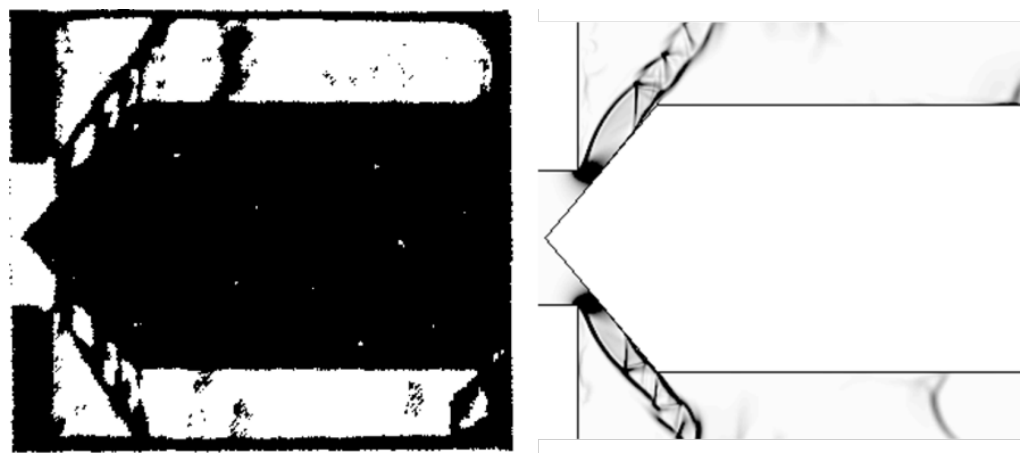

Figure 7 The Schlieren figure observed in experiment (left) and numerical simulation (right).
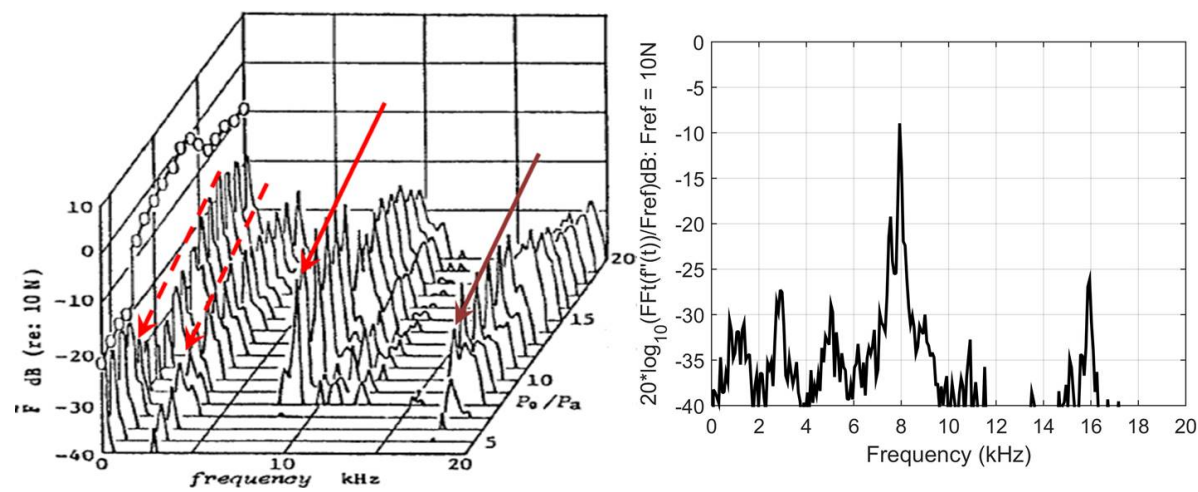

Figure 8 The spectra of the unsteady fluid forces on the spindle; experimental results illustrated in [26] (left) and numerical results (right). 


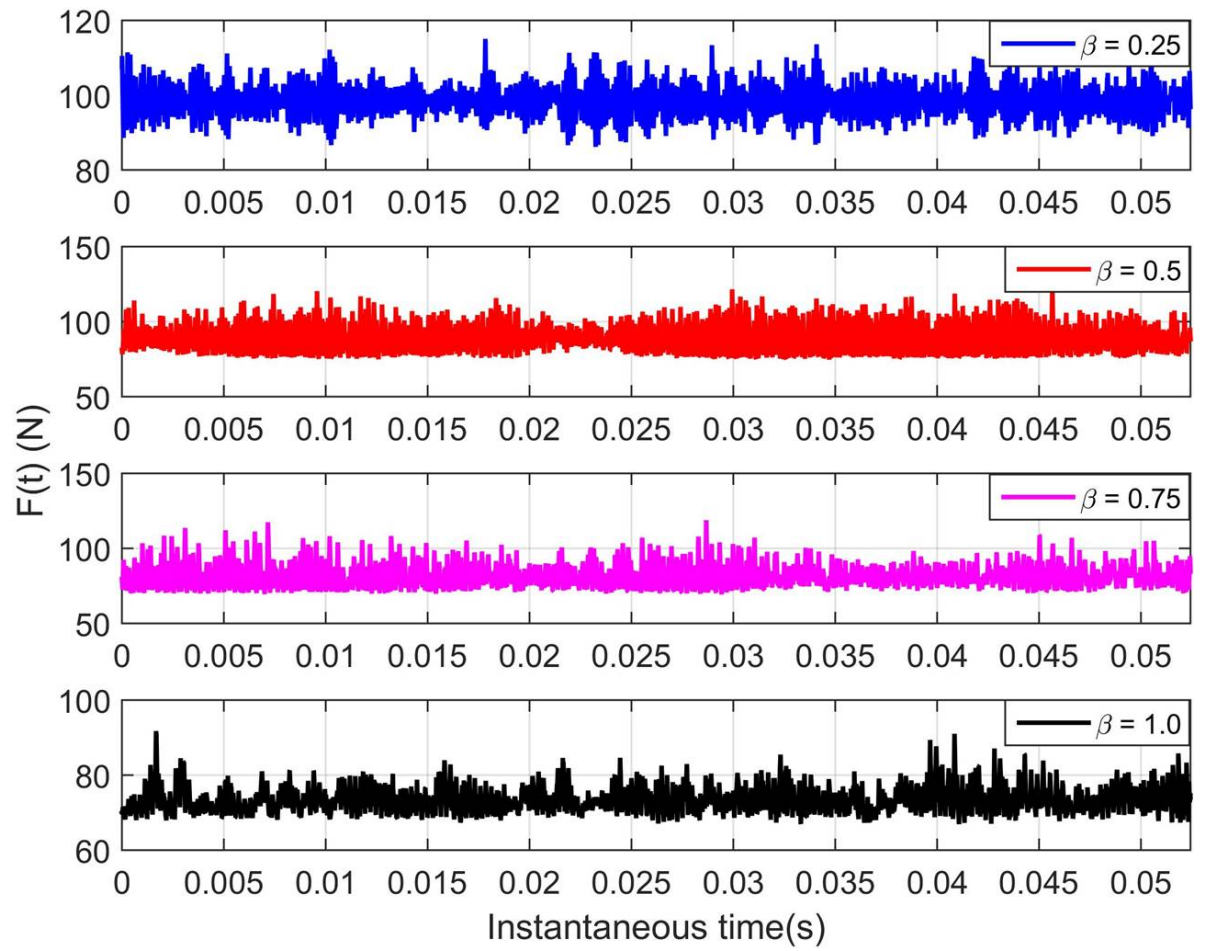

Figure 9 Instantaneous streamwise fluid force on the valve head in the valve with different opening ratios $(\beta)$.
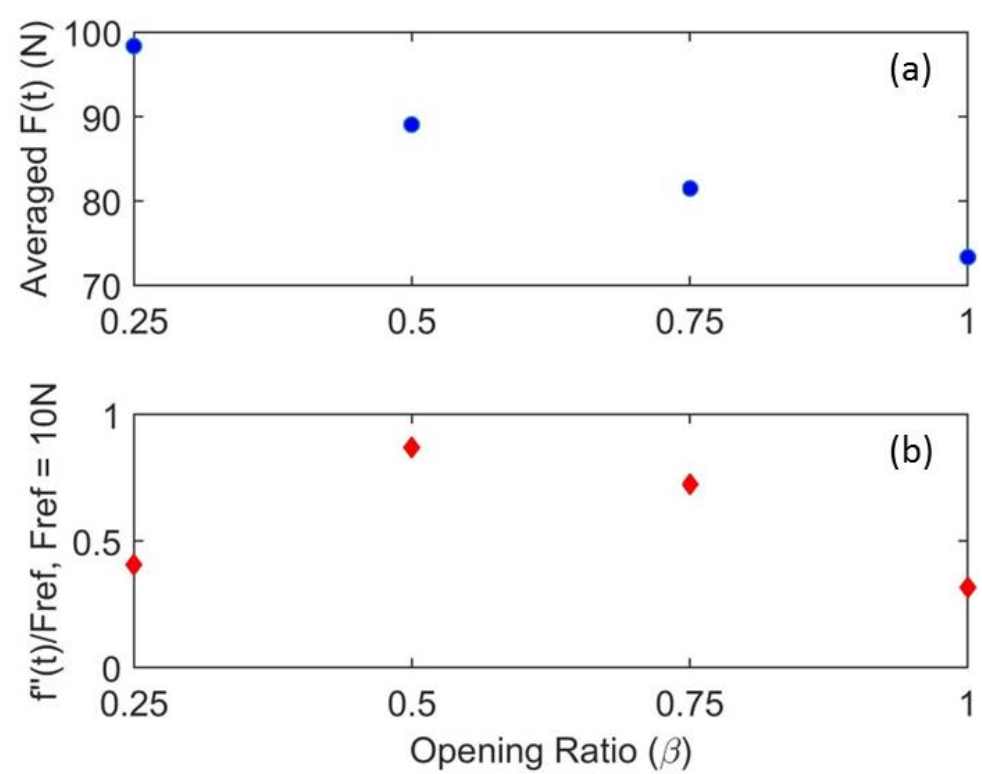

Figure 10 (a) Time-averaged fluid force on the valve head and (b) the r.m.s. of fluctuating components $f^{\prime \prime}(t)$. 


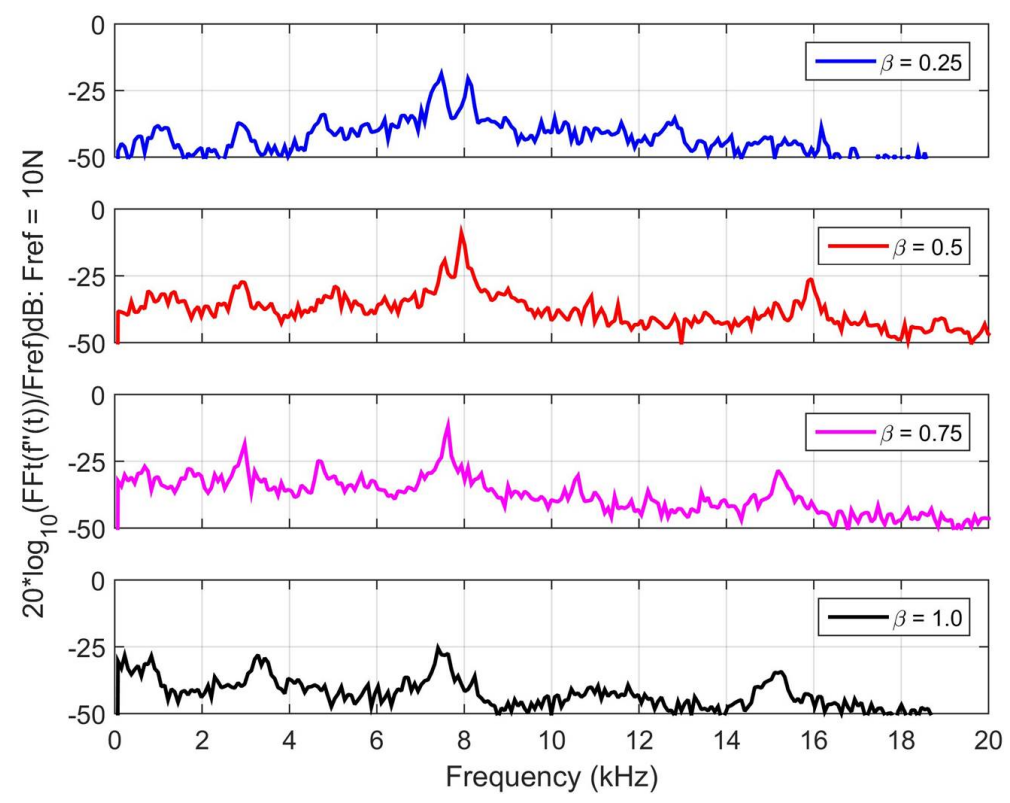

Figure 11 Fast Fourier transform of fluctuating component of instantaneous fluid force on the valve head in the valve with different opening ratios.

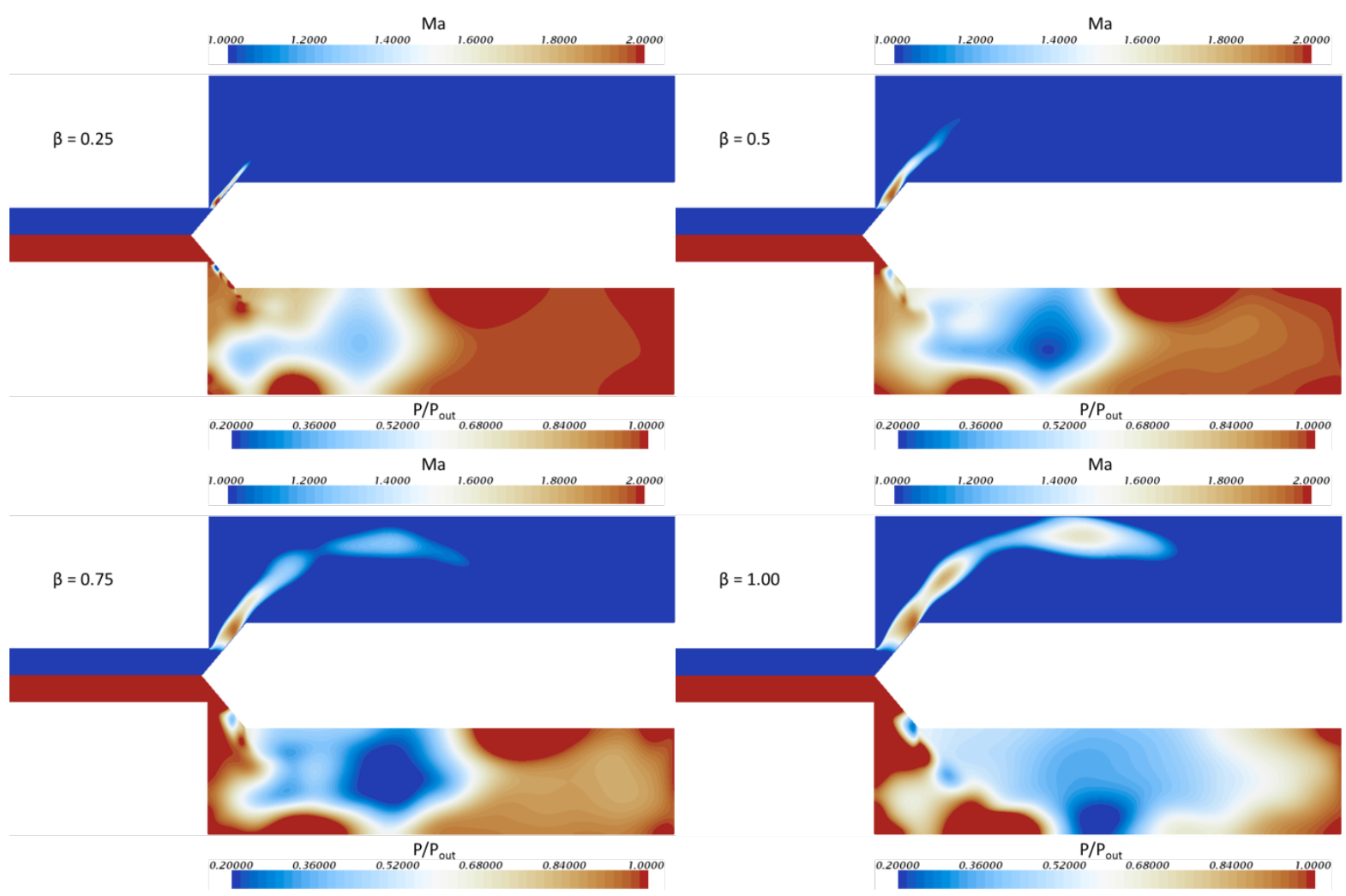

Figure 12 Time-averaged flow field for velocity and pressure for the different opening ratios. 


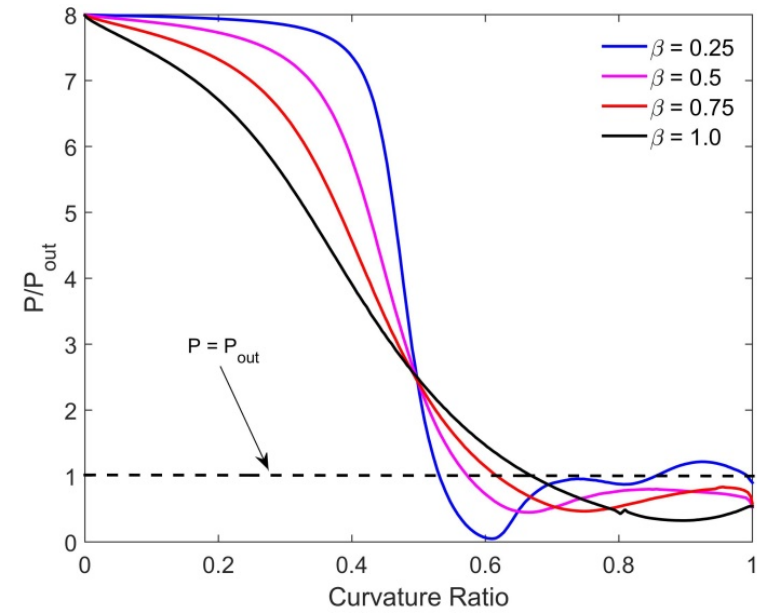

(a)

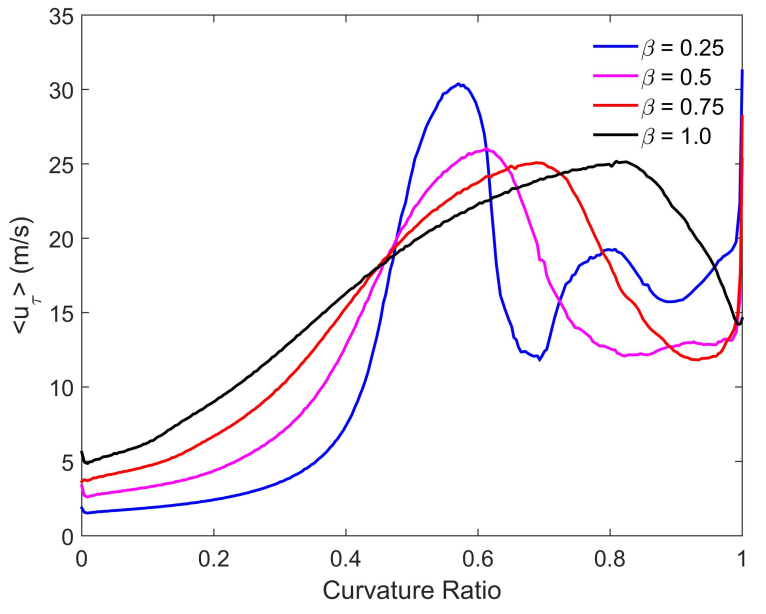

(b)

Figure 13 (a) Normalised averaged pressure $\mathrm{P} / \mathrm{P}_{\text {out }}$ on the conical valve head; (b) Timeaveraged friction velocity $<u_{\tau}>$ on the conical valve head.
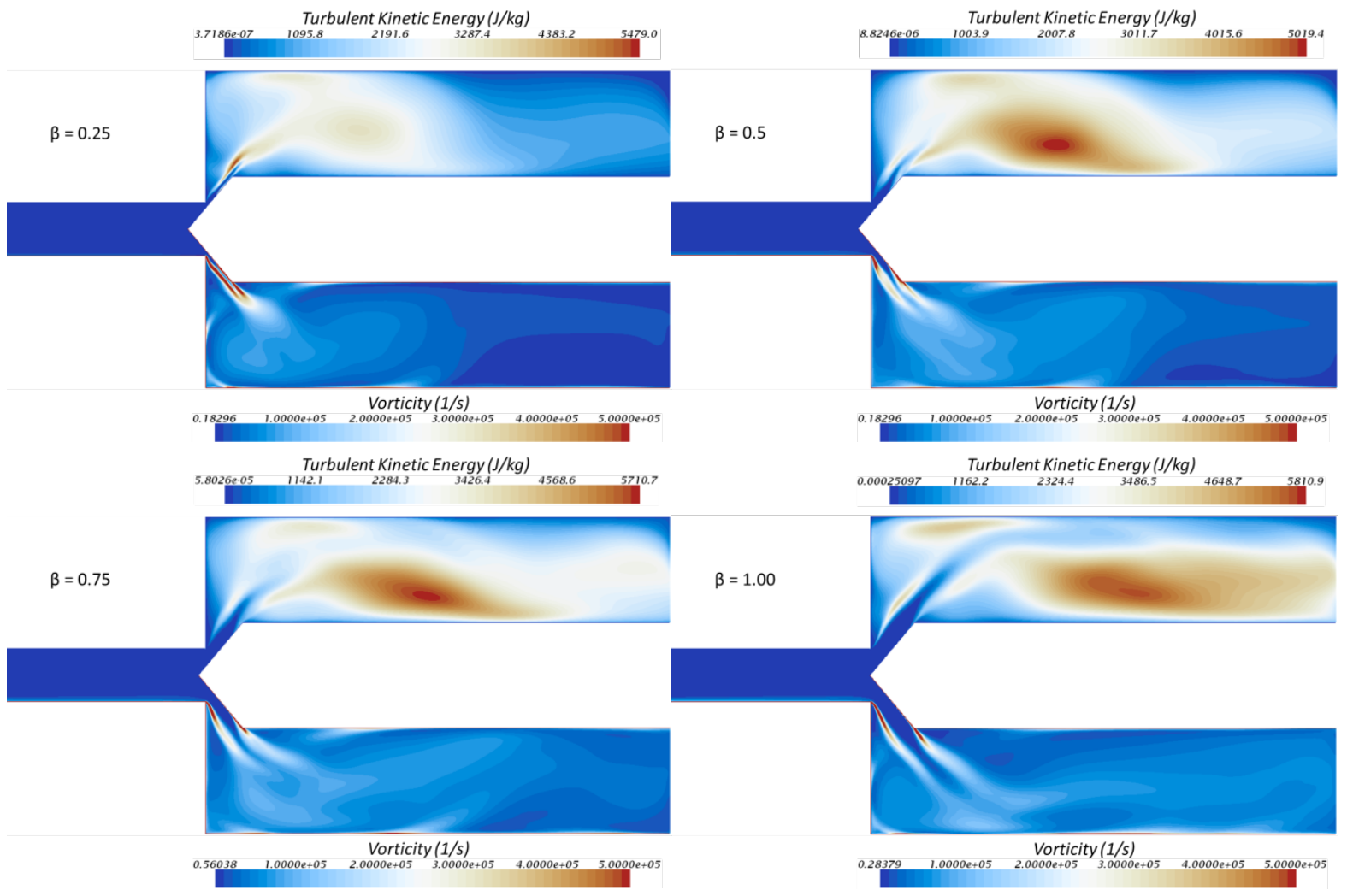

Figure 14 The time-averaged turbulent kinetic energy and vorticity for the four cases.

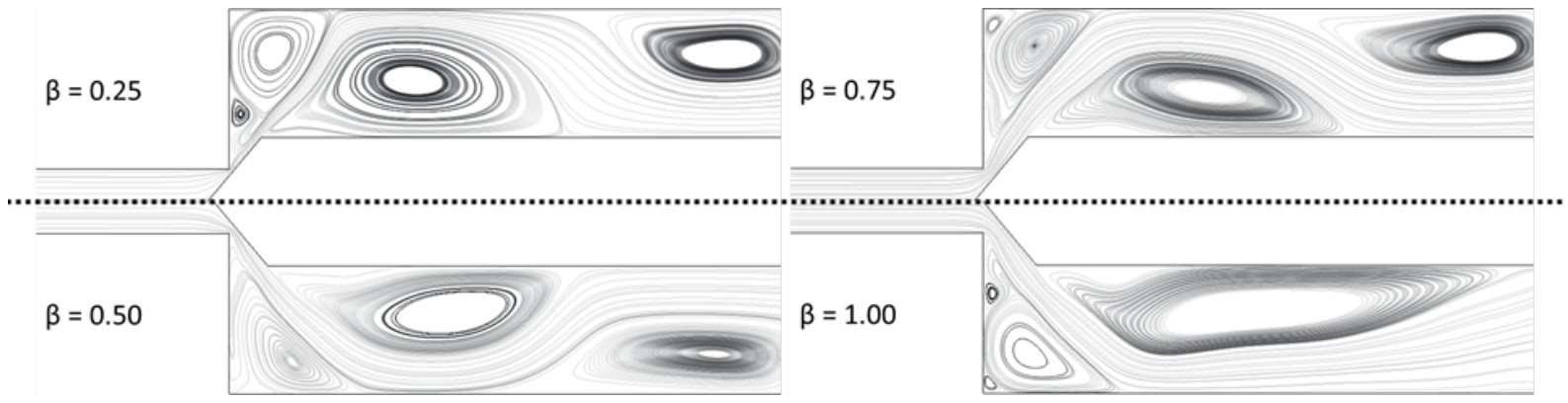

Figure 15 Streamlines of the time-averaged flow for the four cases. 


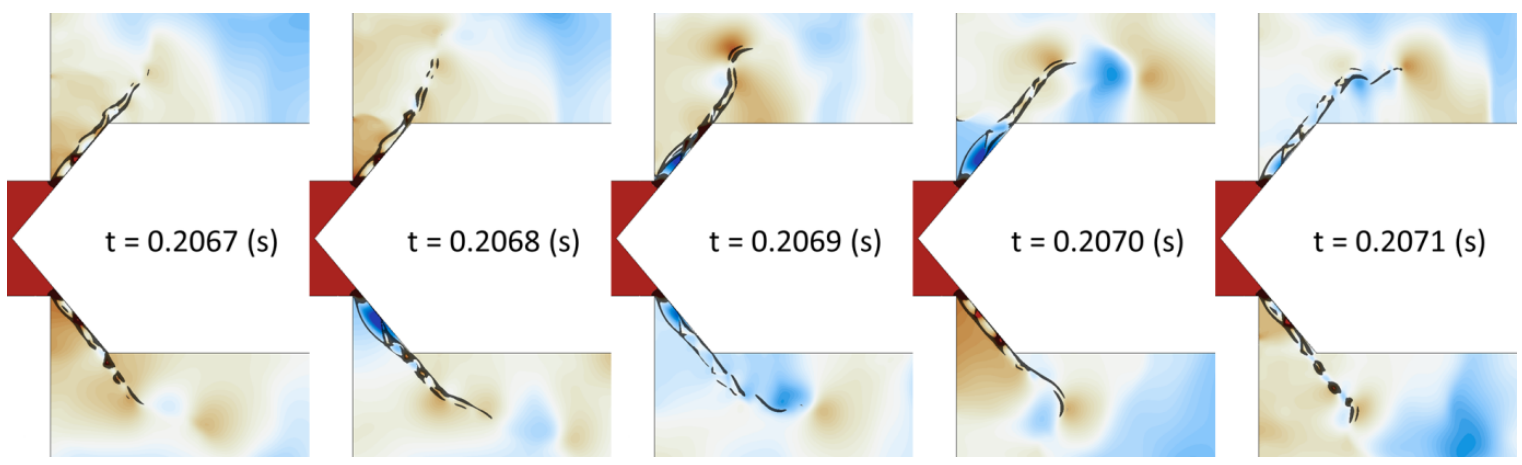

(a) $\beta=0.25$
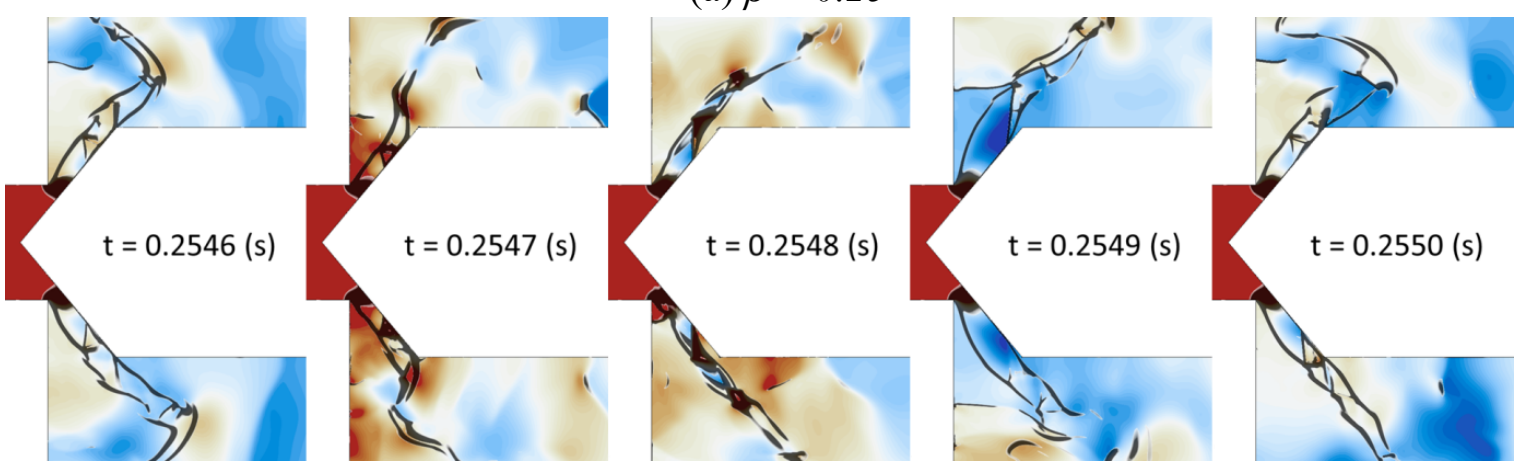

(b) $\beta=0.5$
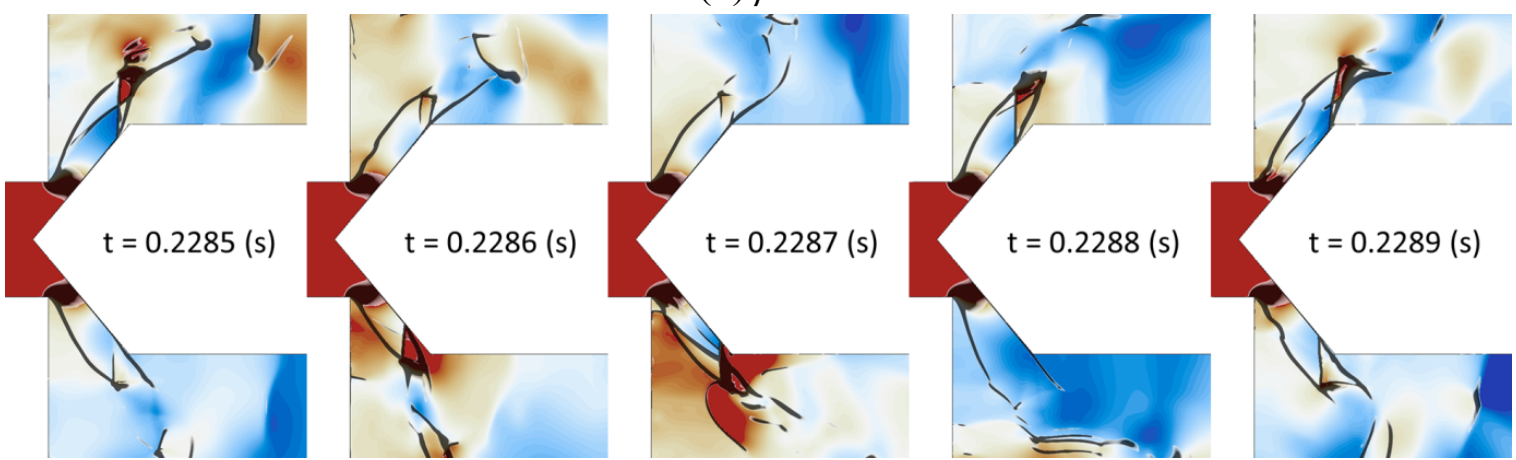

(c) $\beta=0.75$
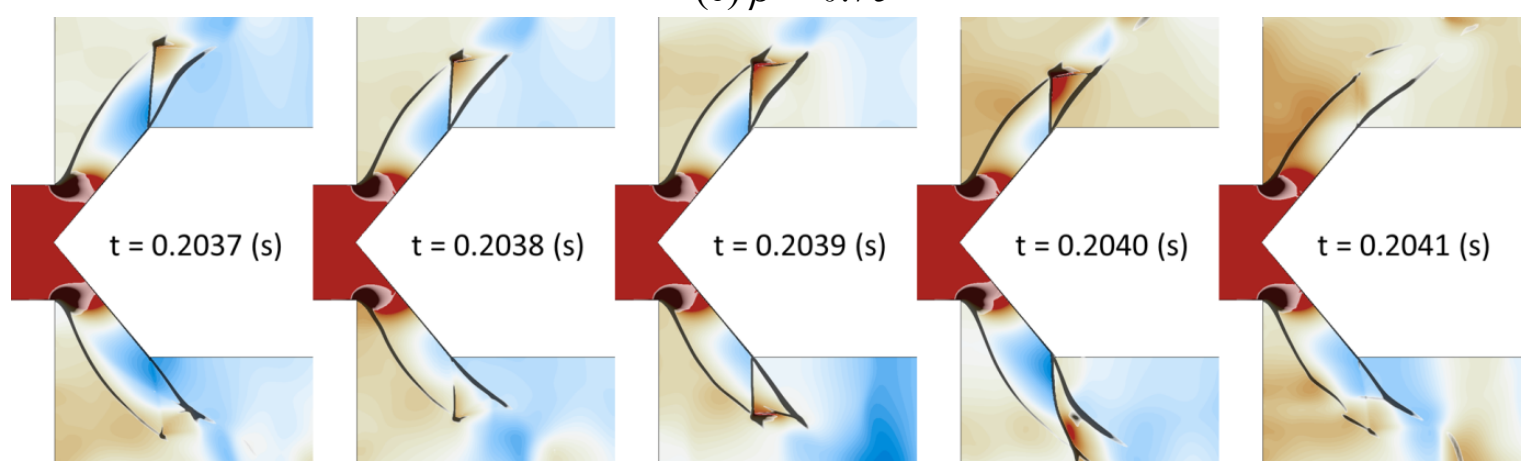

(d) $\beta=1.00$

Figure 16 The transient evolution of pressure contours and shockwaves for the different opening ratios. 


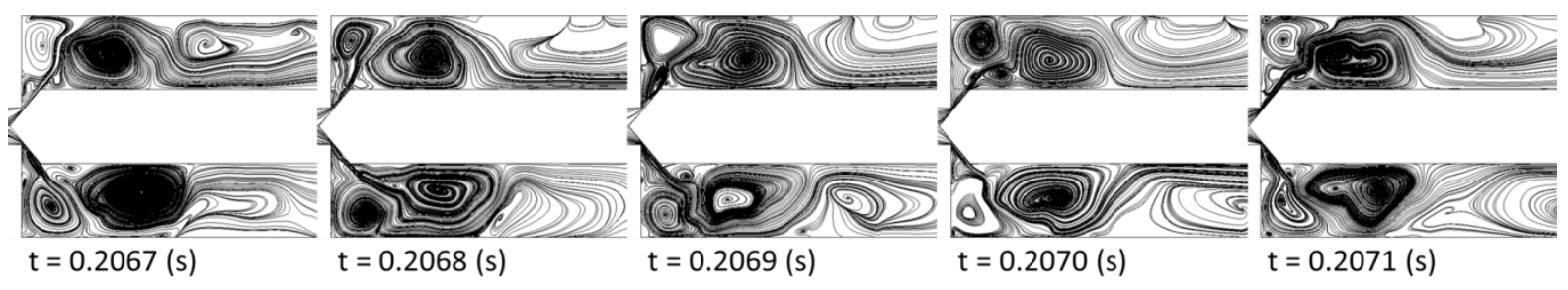

(a) $\beta=0.25$

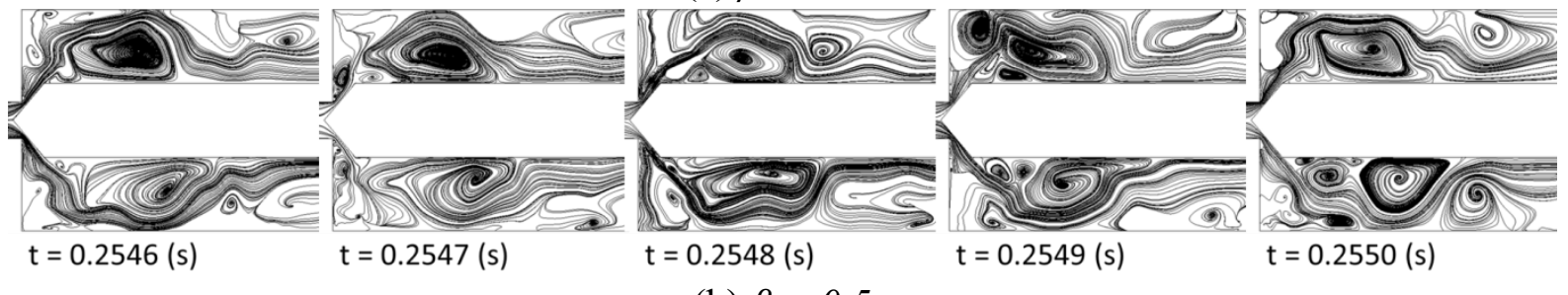

(b) $\beta=0.5$

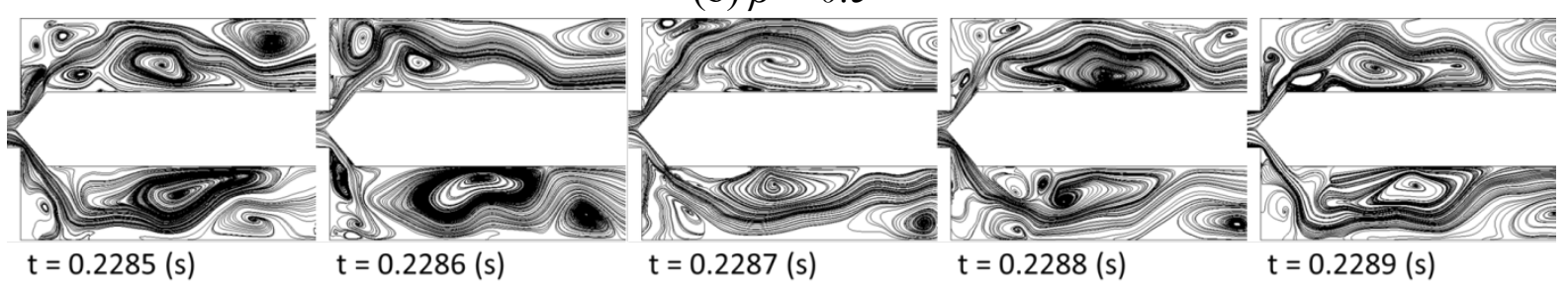

(c) $\beta=0.75$

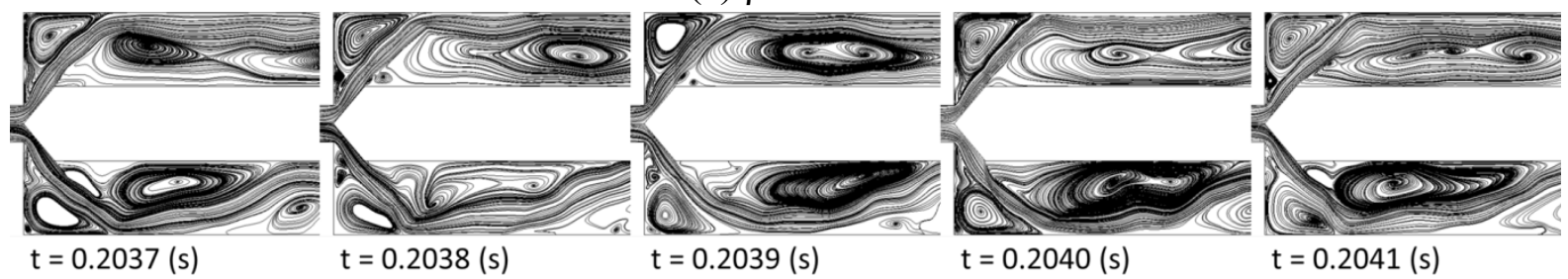

(d) $\beta=1.00$

Figure 17 The transient evolution of velocity streamlines for the different opening ratios. 